\title{
Full Anatomical Recovery of the Dopaminergic System after a Complete Spinal Cord Injury in Lampreys
}

\author{
Blanca Fernández-López, Daniel Romaus-Sanjurjo, María Eugenia Cornide-Petronio, \\ Sonia Gómez-Fernández, Antón Barreiro-Iglesias, and María Celina Rodicio \\ Department of Cell Biology and Ecology, CIBUS, Faculty of Biology, University of Santiago de Compostela, \\ 15782 Santiago de Compostela, Spain
}

Correspondence should be addressed to Antón Barreiro-Iglesias; anton.barreiro@gmail.com and María Celina Rodicio; mcelina.rodicio@usc.es

Received 25 December 2014; Revised 18 February 2015; Accepted 2 March 2015

Academic Editor: Naweed I. Syed

Copyright (C) 2015 Blanca Fernández-López et al. This is an open access article distributed under the Creative Commons Attribution License, which permits unrestricted use, distribution, and reproduction in any medium, provided the original work is properly cited.

Following a spinal injury, lampreys at first are paralyzed below the level of transection. However, they recover locomotion after several weeks, and this is accompanied by the regeneration of descending axons from the brain and the production of new neurons in the spinal cord. Here, we aimed to analyse the changes in the dopaminergic system of the sea lamprey after a complete spinal transection by studying the changes in dopaminergic cell numbers and dopaminergic innervation in the spinal cord. Changes in the expression of the D2 receptor were also studied. We report the full anatomical regeneration of the dopaminergic system after an initial decrease in the number of dopaminergic cells and fibres. Numbers of dopaminergic cells were recovered rostrally and caudally to the site of injury. Quantification of dopaminergic profiles revealed the full recovery of the dopaminergic innervation of the spinal cord rostral and caudal to the site of injury. Interestingly, no changes in the expression of the D2 receptor were observed at time points in which a reduced dopaminergic innervation of the spinal cord was observed. Our observations reveal that in lampreys a spinal cord injury is followed by the full anatomical recovery of the dopaminergic system.

\section{Introduction}

In humans, complete spinal cord injuries cause an irreversible loss of function below the site of lesion and lead to permanent disability. This is mainly due to the absence of regeneration of descending axons and the failure of replacement of damaged spinal neurons. In contrast, lampreys spontaneously recover locomotion after a complete spinal cord injury [1]. During the recovery process lampreys are able to regenerate axotomized descending axons [2-4] and produce new spinal neurons [5]. Recent studies have also shown that different neurotransmitters systems adapt and show plastic changes after a spinal cord injury in lampreys, which could also contribute to the recovery of function (serotonergic system: [6, 7]; aminoacidergic systems: [8-10]). So, both regeneration and plasticity events appear to contribute to the spontaneous recovery of function in lampreys. It is of great biological interest to study the amazing response of lampreys to a spinal cord injury and specifically how the different neurotransmitter systems react to the injury.
The spinal cord receives inputs from different neurotransmitter systems located in the brain. Among them, the monoaminergic systems (i.e., dopaminergic, serotonergic, and noradrenergic systems) play an important role in the modulation of spinal locomotor circuits. Historically, more efforts have been put on the study of the serotonergic spinal system than on the dopaminergic one. However, across different species dopamine has profound and diverse effects on rhythmically active motor networks (for a recent review see [11]). In lampreys, dopamine elicits a complex modulatory effect on swimming behavior. Low dopamine concentrations $(0.1-10 \mu \mathrm{M})$ result in an increase in locomotor frequency, while higher concentrations $(10-100 \mu \mathrm{M})$ slow the rhythm, and concentrations of $100 \mu \mathrm{M}-1 \mathrm{mM}$ can suppress the rhythm [12-14]. The increase in locomotor frequency can be reproduced in freely swimming animals [15] and appears to be mediated by D2 receptors [12]. Concentration dependent dopamine effects are also observed in tadpoles, where dopamine reduces locomotor activity via D2-like mechanisms at low concentrations $(2 \mu \mathrm{M})$ and promotes 
locomotor activity at higher concentrations $(50 \mu \mathrm{M})$ via D1like mechanisms [16]. In mammals, dopamine is able to promote locomotion when introduced to the intact animal [17]. In vitro preparations of fictive locomotion of the neonatal rodent spinal cord have shown that dopamine can activate fictive locomotor activity in rats [18, 19], but not in mice, although D1 agonist alone can be sufficient for locomotion in mice [20]. In mammals, dopamine may be promoting ongoing locomotor activity through the activation of D1-like receptors, while the slowing effect of dopamine on fictive locomotor frequency is through D2-like receptor mechanisms (for a review see [11]). Previous research shows that dopamine plays an important role in the modulation and control of locomotion in vertebrates, from lampreys to mammals.

Interestingly, recent reports have also shown the importance of dopamine signalling not only during normal locomotion, but also in the recovery of locomotion following spinal cord injury in mammals [21-23] or of dopamine as a signal controlling spinal cord development and regeneration in zebrafish $[24,25]$. This reveals that dopamine could also be a key player for regeneration and the recovery of function after spinal cord injury in vertebrates.

Here, we report a study of the anatomical changes that occur in the dopaminergic system of lampreys after a complete spinal cord injury and during the recovery period by studying: (1) the changes in the dopaminergic innervation of the spinal cord, (2) the changes in dopaminergic cell numbers, and (3) the changes in the expression of the dopamine D2 receptor in the spinal cord. We aimed to investigate if lampreys recover or adapt the dopaminergic system during the process of functional recovery after a complete spinal cord injury and compare this process to other regenerating and nonregenerating vertebrates. The source of spinal dopamine in mammals is the descending hypothalamic projection [26], which is also present in lampreys [27] and all the other vertebrates [26]. This high degree of conservation facilitates a comparison between lampreys and other vertebrates in terms of recovery of the dopaminergic innervation of the spinal cord after an injury. However, it is also of interest that lampreys, as opposed to other vertebrates, have intrinsic dopaminergic cells in the spinal cord. So, our study also offers a new model to study the spontaneous recovery of dopaminergic cells after a traumatic injury in vertebrates.

\section{Material and Methods}

2.1. Animals. Mature and developmentally stable larval sea lampreys (Petromyzon marinus L., $>100 \mathrm{~mm}$ body length, 4 to 7 years of age) were used for the present investigation. Larval sea lampreys were collected from the river Ulla (Galicia, Spain) with permission from the Xunta de Galicia and maintained in aerated fresh water aquaria at $16^{\circ} \mathrm{C}$ with a bed of river sediment until their use for experimental procedures. All animal experimental procedures were approved by the Bioethics Committee at the University of Santiago de Compostela and complied with Spanish and European guidelines for the care and use of animals in research.
2.2. Complete Spinal Cord Transection. Before surgery, animals were deeply anaesthetized by immersion in $0.1 \%$ tricaine methanesulfonate (MS-222; Sigma, St. Louis, MO). A complete transection of the spinal cord was performed with a scalpel at the level of the 5th gill as previously described $[4,7]$. Animals $(n=33)$ were allowed to recover for $2(n=13)$, $4(n=10), 10(n=5)$, or $24(n=5)$ weeks after lesion (wpl). Visual observations indicated that normal appearing swimming behaviour was present in the 5 animals processed at $24 \mathrm{wpl}$. Control unlesioned animals $(n=12)$ were always processed in parallel with lesioned animals.

\subsection{Dopamine Immunohistochemistry. Dopamine immuno-} fluorescence experiments were performed in $14 \mu \mathrm{m}$ transverse cryostat spinal cord sections of control and lesioned animals using a rabbit anti-dopamine antibody (1 : 750; Dr. Steinbusch, Maastricht University) and as previously described [28]. Ten spinal cord hemisections (one spinal cord side) were photographed $450 \mu \mathrm{m}$ both rostrally and caudally to the site of injury with the confocal spectral microscopes TCSSP2 and SP5 (Leica, Wetzlar, Germany). In control animals, 20 sections at the level of the 5th gill were photographed. One out of three consecutive sections was photographed in unlesioned and lesioned (rostral and caudal) animals. The semiautomatic quantification of the number of dopamine immunofluorescent profiles per hemisection (the hemisection was randomly chosen for each section) was done using Image J and as previously described for the quantification of monoaminergic or aminoacidergic positive profiles in spinal cord transverse sections of zebrafish and lampreys $[9,29,30]$.

2.4. Cell Counts. Two types of dopaminergic spinal cells were quantified: ventromedial (VM) and cerebrospinal fluidcontacting (CSFc) cells. The number of cells in the rostral and caudal spinal cord was obtained from stereological counts of stacks of confocal images from the 10 spinal cord sections rostral and 10 caudal to the lesion site (1 out of 3 consecutive sections) as previously described [30]. Stereological counting was performed discarding the cells located in the first optical section of the confocal stack of each spinal cord section. The number of cells in $450 \mu \mathrm{m}$ was estimated from the number of cells counted in each spinal section and then the mean number of cells in $450 \mu \mathrm{m}$ was calculated for each animal from the results of the 10 sections separately counted for the rostral and caudal spinal cord.

2.5. In Situ Hybridization. In situ hybridization for the detection of dopamine D2 receptor transcripts was performed in cryostat transverse spinal cord sections of control unlesioned and spinal transected animals. In situ hybridization experiments were performed as previously described for riboprobes against the serotonin la receptor (5-htla) [31]. The riboprobe against the sea lamprey D2 receptor transcript was generated by using the following primers $5^{\prime}-\mathrm{GTG}$ CCCTCTTCTCTTTGGCT- $3^{\prime}$ (forward) and $5^{\prime}$-TAAGCTTTAATACGACTCACTATAGGGAGAAAGAAGGGCATCCAGCAGAC-3' (reverse). These primers were generated based on the river lamprey (Lampetra fluviatilis) D2 receptor 
mRNA sequence deposited in the NCBI GenBank (GenBank accession number: HQ331119 [31]). The reverse primer includes the sequence of the $\mathrm{T} 7$ promoter for riboprobe generation. Digoxigenin- (DIG-) labeled riboprobes were synthesized using the amplified fragments as templates and following standard protocols using T7 polymerase (Roche Diagnostics, Germany).

As previously shown by others, D2 in situ signal appears as a dotted labelling in sections of the lamprey central nervous system $[32,33]$. The semiautomatic quantification of the number of these positive D2 profiles per spinal cord hemisection was done as previously described for the quantification of 5-htla positive profiles, which also produced a dotted in situ labelling [7].

2.6. Statistical Analyses. For statistical analysis, the program Prism (GraphPad Software, La Jolla, CA) was used. Variability of values is always given as SEM. Normality was analysed with the Kolmogorov-Smirnov normality test. Data sets that passed the normality test were analysed for statistical significance with a One-Way ANOVA. Data sets that did not pass the normality test were analysed for statistical significance with the Kruskal-Wallis One-Way ANOVA for nonnormally distributed data. Bonferroni's or Dunn's multiple comparison tests were used to compare pairs of data.

\section{Results}

3.1. Dopamine Immunoreactivity in Unlesioned Control Animals. At the level of the 5 th gill the spinal cord of mature larval sea lamprey shows the presence of two main types of dopamine immunoreactive (-ir) cells: CSFc cells that are located in the ventral portion of the central canal and nonCSFc cells that are located in the ventromedial region of the spinal cord (VM cells) (Figure 1(a)). In addition, very scarce dopamine-ir cells were occasionally observed in the lateral or dorsal grey (not shown). Here, we analysed the changes in the number of cells for the two main dopamine-ir populations, CSFc and VM cells, during spinal cord regeneration after a complete spinal cord transection.

At this spinal cord level, dopamine-ir fibres are observed mainly in the ventromedial region of the white matter, below the giant reticulospinal axons, forming a dense plexus of varicose fibres (Figures $1(\mathrm{a})$ and $2(\mathrm{a})$ ). This plexus appears to be constituted primarily by processes of the VM dopamineir cells [13]. Dopamine-ir fibres are also observed in the lateral column and in the dorsal region of the white matter (Figure 2(a)). The distal processes of the dopamine-ir CSFC cells can be traced to the lateral cell column, the ventral area of the dorsal column, and to the ventromedial region of the cord [34]. Dopaminergic spinal-projecting neurons have been also reported in the brain of the sea lamprey [27]; therefore, some of the dopamine-ir fibres at this spinal cord level probably belong to the descending dopaminergic projections.

3.2. D2 Receptor Expression in Unlesioned Animals. At the level of the 5th gill, D2 transcript expression was observed in most of the spinal cord neurons: dorsal cells, motor neurons, and interneurons (Figure 3). No expression of the D2 transcript was observed in edge cells. The dorsal cells showed a group of positive dots in their soma (Figure 3(a)). D2 transcript expression was observed in interneurons of different sizes and morphologies located throughout the dorsal and lateral grey matter (Figure 3(b)). Expression of the D2 transcript was also observed in cells that were identified as spinal motor neurons based on their morphology and location in the spinal motor column (Figure 3(c)). Finally, expression of D2 transcripts was also observed in cells surrounding the central canal (CSFc and ependymal glial cells) with granules of positive expression in their somas and in the dendrites of CSFc cells (Figure 3(d)). The expression of the D2 transcript has also been recently described in the rostral spinal cord of the adult river lamprey [33], and the pattern of expression appears to be very similar between the larval sea lamprey (present results) and the adult river lamprey [33].

3.3. Dopaminergic Cell Numbers Are Recovered after a Complete Spinal Cord Transection. The changes in dopamine-ir cell numbers are shown in Figures 1 and 4 . Rostral to the site of injury, at $2 \mathrm{wpl}$, we found a $31.7 \%$ (nonsignificant) lower number of CSFc dopamine-ir cells as compared to unlesioned animals. At $24 \mathrm{wpl}$ the number of CSFc dopamine-ir cells rostral to the site of injury was significantly increased to $121.6 \%$ as compared to $2 \mathrm{wpl}$ and was not significantly different to unlesioned animals (Figures 1 and ??).

Caudal to the site of injury, at $2 \mathrm{wpl}$, we found a significant $42.5 \%$ lower number of CSFc dopamine-ir cells as compared to unlesioned animals. At $24 \mathrm{wpl}$ the number of CSFc dopamine-ir cells caudal to the site of injury was significantly increased to $120.9 \%$ as compared to $2 \mathrm{wpl}$ and was not significantly different to unlesioned animals. The number of CSFc dopamine-ir cells caudal to the site of injury was already significantly increased to $106.9 \%$ at $10 \mathrm{wpl}$ as compared to $2 \mathrm{wpl}$ (Figures 1 and ??).

Rostral to the site of injury, at 2 and $4 \mathrm{wpl}$, we found a significant $73.5 \%$ and $51.9 \%$ lower number of VM dopamineir cells, respectively, as compared to unlesioned animals. At $24 \mathrm{wpl}$ the number of VM dopamine-ir cells rostral to the site of injury was significantly increased to $119.4 \%$ as compared to 2 and $4 \mathrm{wpl}$ and was not significantly different to unlesioned animals. The number of VM dopamine-ir cells rostral to the site of injury was already significantly increased to $85.1 \%$ at $10 \mathrm{wpl}$ as compared to $2 \mathrm{wpl}$ (Figures 1 and ??).

Caudal to the site of injury, at $2 \mathrm{wpl}$, we found a significant $70.8 \%$ lower number of VM dopamine-ir cells as compared to unlesioned animals. At 24 wpl the number of VM dopamineir cells caudal to the site of injury was significantly increased to $141.2 \%$ as compared to $2 \mathrm{wpl}$ and was not significantly different to unlesioned animals (Figures 1 and ??).

3.4. The Dopaminergic Innervation of the Spinal Cord Is Recovered after a Complete Spinal Cord Transection. The changes in the dopamine-ir innervation of the spinal cord are shown in Figures 2 and 5 . Rostral to the site of injury, at $2 \mathrm{wpl}$, we found 


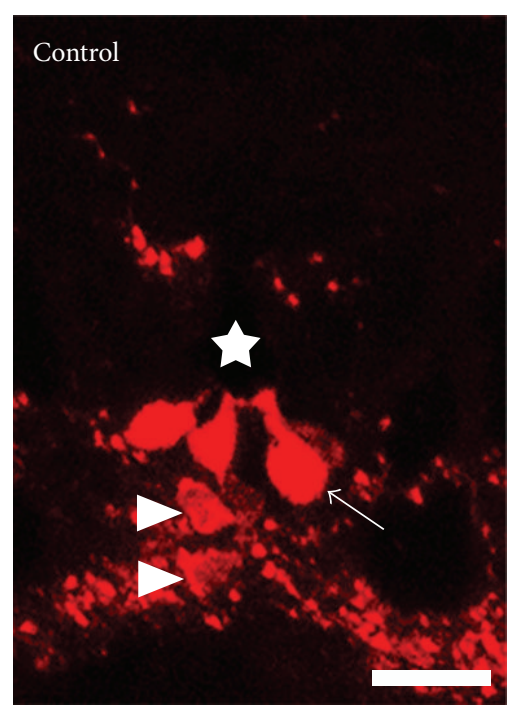

(a)

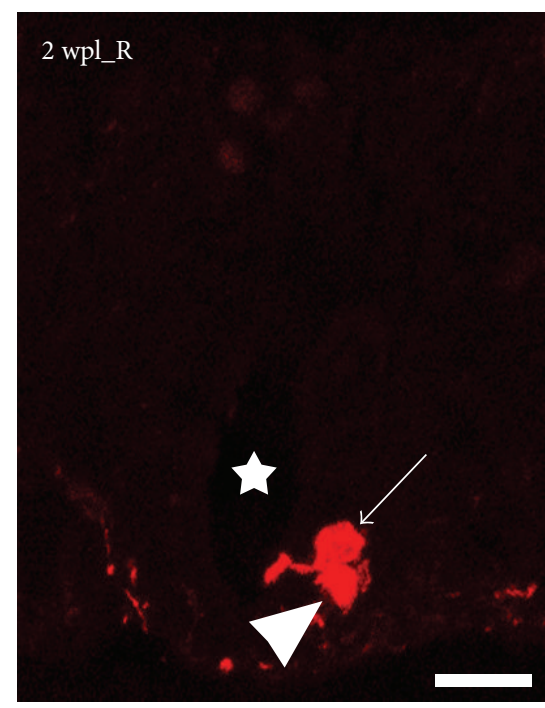

(b)

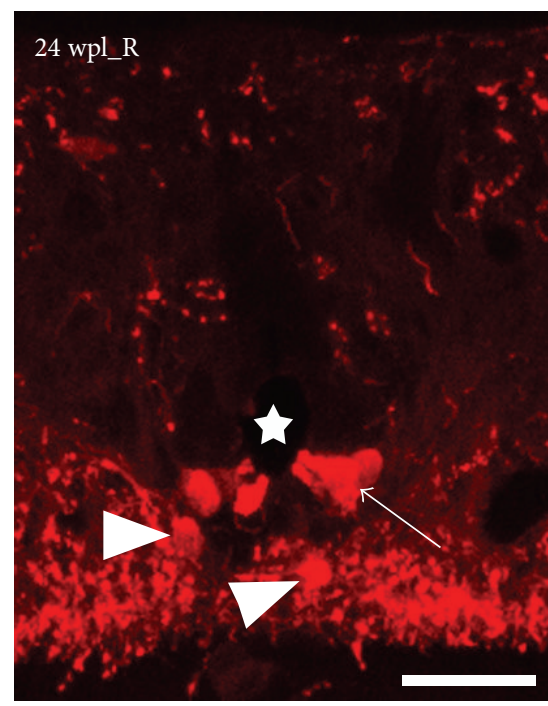

(c)

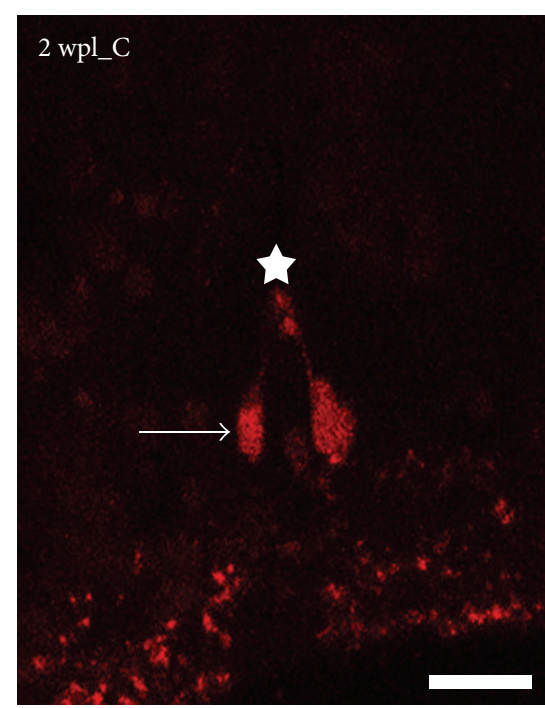

(d)

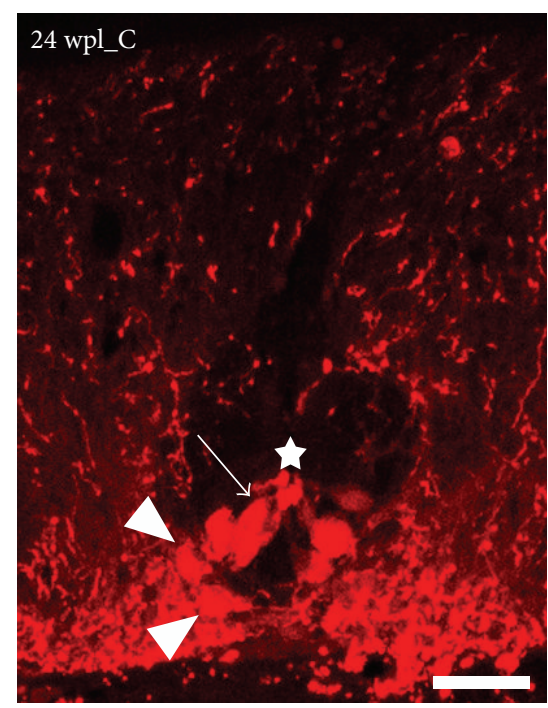

(e)

Figure 1: Confocal photomicrographs of transverse sections of the spinal cord showing details of the dopaminergic cells in control and lesioned animals. (a) Dopaminergic cells in a control unlesioned larva. ((b), (d)) Dopaminergic cells in a 2 wpl larva, rostral (b) and caudal (d) to the site of injury. ((c), (e)) Dopaminergic cells in a $24 \mathrm{wpl} \mathrm{larva,} \mathrm{rostral} \mathrm{(c)} \mathrm{and} \mathrm{caudal} \mathrm{(e)} \mathrm{to} \mathrm{the} \mathrm{site} \mathrm{of} \mathrm{injury.} \mathrm{CSFc} \mathrm{cells} \mathrm{(arrows),} \mathrm{VM}$ cells (arrowheads), star points to the central canal. In all photomicrographs dorsal is at the top. Scale bars $=25 \mu \mathrm{m}$.

a significant $74.8 \%$ lower number of dopaminergic profiles per spinal cord hemisection as compared to unlesioned animals. At $24 \mathrm{wpl}$ the number of dopaminergic profiles per spinal cord hemisection rostral to the site of injury was significantly increased to $105.3 \%$ as compared to $2 \mathrm{wpl}$ and was not significantly different to unlesioned animals. The number of dopaminergic profiles per spinal cord hemisection rostral to the site of injury was already significantly increased to $86.8 \%$ and $89.8 \%$ at $4 \mathrm{wpl}$ and $10 \mathrm{wpl}$, respectively, as compared to $2 \mathrm{wpl}$ (Figures 2 and 5(a)).

Caudal to the site of injury, at $2 \mathrm{wpl}$, we found a significant $75.4 \%$ lower number of dopaminergic profiles per spinal cord hemisection as compared to unlesioned animals. At $24 \mathrm{wpl}$ the number of dopaminergic profiles per spinal cord hemisection rostral to the site of injury was significantly increased to $131.6 \%$ as compared to $2 \mathrm{wpl}$ and was not significantly different to unlesioned animals (Figures 2 and 5(b)).

\subsection{The Spinal Cord Injury and a Reduced Dopaminergic} Innervation Do Not Affect the Expression of the D2 Receptor Transcript in the Sea Lamprey Spinal Cord. In a previous study we identified acute changes in the expression of 5htla transcripts after a complete spinal cord transection in the larval sea lamprey [7]. Here, we quantified the number of D2 positive in situ profiles in hemisections of the spinal cord, both rostral and caudal to the lesion site at 2 and $4 \mathrm{wpl}$, 


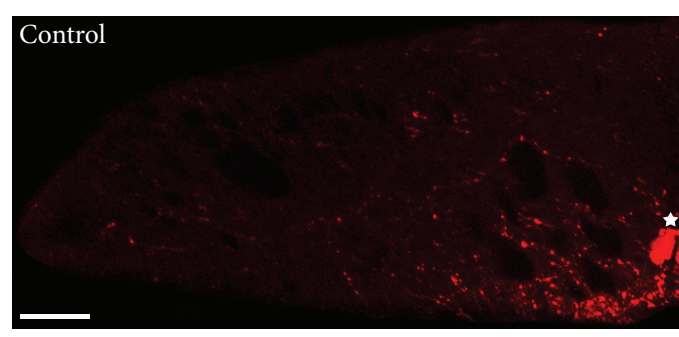

(a)

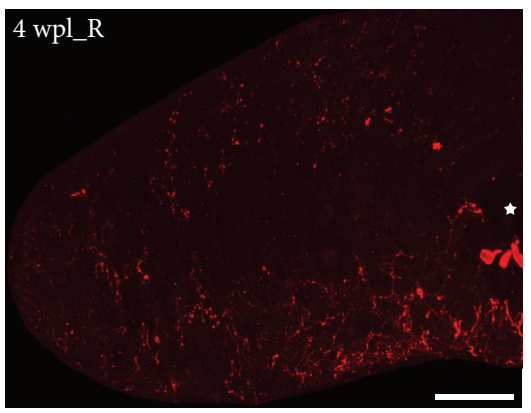

(c)

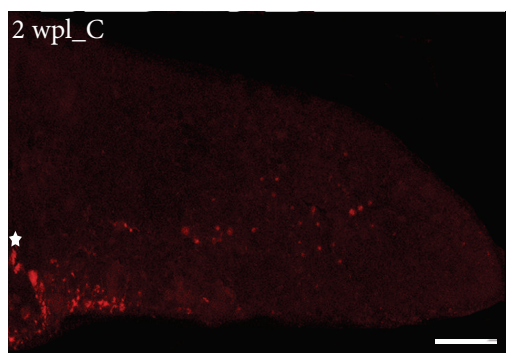

(e)

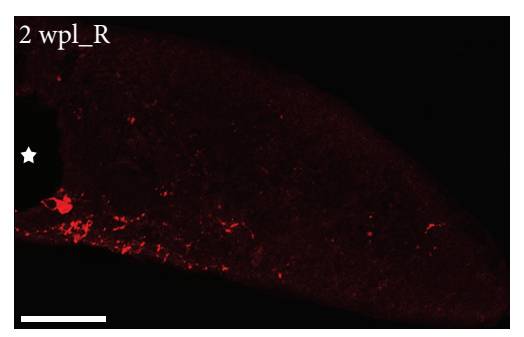

(b)

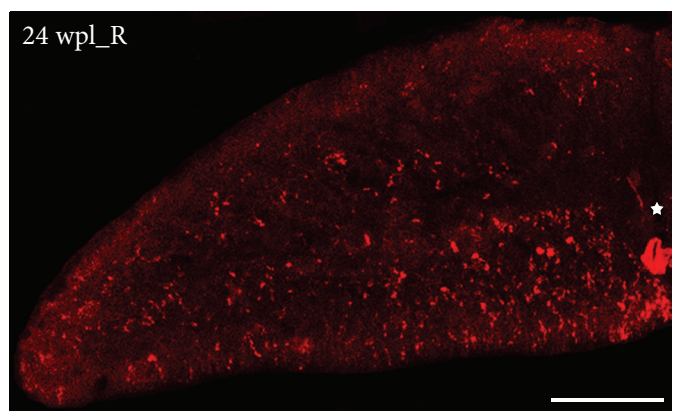

(d)

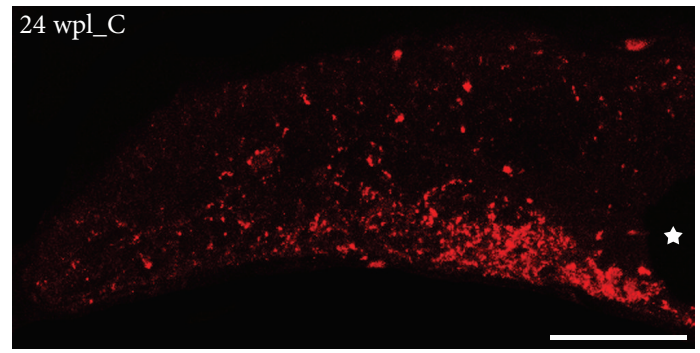

(f)

FIGURE 2: Confocal photomicrographs of transverse sections of the spinal cord showing details of the dopaminergic innervation of the spinal cord in control and lesioned animals. (a) Dopamine-ir fibers in a control unlesioned larva. (b) Dopamine-ir fibers in the rostral stump of a 2 wpl larva. (c) Dopamine-ir fibers in the rostral stump of a 4 wpl larva. (d) Dopamine-ir fibers in the rostral stump of a $24 \mathrm{wpl} \mathrm{larva.} \mathrm{(e)}$ Dopamine-ir fibers in the caudal stump of a 2 wpl larva. (f) Dopamine-ir fibers in the caudal stump of a 24 wpl larva. Star indicates the central canal. In all microphotographs dorsal is at the top. Scale bars $=50 \mu \mathrm{m}$.

and in unlesioned larvae (Figure 6). Compared to control unlesioned values, no significant differences were observed in the number of D2 profiles per hemisection in the rostral (One-Way ANOVA, $P=0.2490$ ) or caudal (Kruskal-Wallis ANOVA, $P=0.6210$ ) stumps of the spinal cord at 2 or $4 \mathrm{wpl}$ (Figure 6). This indicated that the complete spinal cord injury and/or the initial decrease (at 2 to $4 \mathrm{wpl}$ ) in dopaminergic fibres and cells do not induce changes in the expression of D2 receptor transcripts in the sea lamprey.

\section{Discussion}

Our study shows that a high and complete spinal cord injury in lampreys causes initial decrease in the number of dopaminergic cells and fibres in the spinal cord, which is followed by the full anatomical recovery of the dopaminergic spinal system. This is in contrast to the glutamatergic system, which is not fully recovered 6 months after a complete spinal cord injury in lampreys, even in the presence of functional recovery [10]. Both the dopaminergic innervation of the spinal cord (rostral and caudal to the site of injury) and the number of dopaminergic intrinsic spinal cells are fully recovered 6 months after the complete spinal cord injury. These results indicate that, in lampreys, each neurotransmitter system responds differently to the spinal cord injury to achieve functional recovery. The importance of each of these changes and the interaction between the different neurotransmitter spinal systems (i.e., metaplasticity) for the recovery of function should be analysed in future studies. The analysis of our present observations points to several interesting facts that we discuss here.

When looking at changes in the number of cells, we observed a faster recovery of the number of CSFc dopamineir cells than that of VM dopamine-ir cells after the complete spinal cord injury. Although we cannot assure that these are newly generated cells, the fact that the number of VM cells is recovered later could reflect the time needed for the differentiation and migration of these cells after regeneration from 

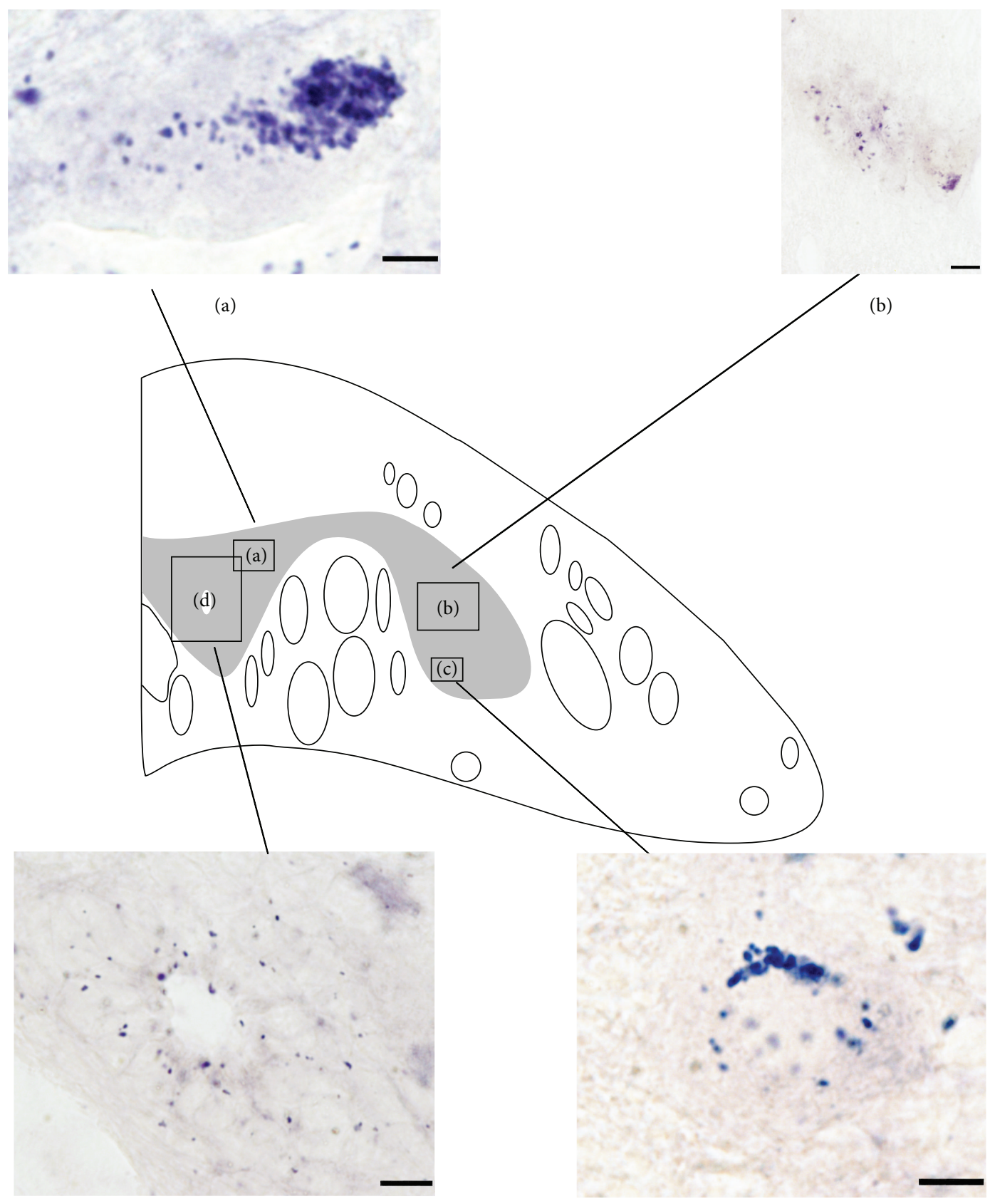

(d)

(c)

FIGURE 3: Expression of the D2 receptor in control animals. (a) Dorsal cell showing expression of the D2 transcript in its soma. (b) Interneurons showing expression of D2 transcript. (c) Expression of D2 transcripts in CSFc and ependymal glial cells around the central canal. (d) Expression D2 transcripts in spinal motor neurons. In all microphotographs dorsal is at the top. Scale bars $=50 \mu \mathrm{m}$.

ependymal progenitor cells located around the central canal. Several types of interneurons as well as motor neurons of adult zebrafish, another regenerating vertebrate, are regenerated after a complete spinal cord injury from ependymoradial glial cells located around the central canal [25, 30, 35-37]. A recent study has also reported the production of new neurons after a complete spinal cord injury in lampreys based on the colocalization of BrdU and the neuronal marker $\mathrm{Hu}$ [5]. Present and past results suggest that dopaminergic cells could be newly generated after the injury in lampreys. Interestingly, Zhang and coworkers [5] reported that in lampreys the newly generated neurons where observed only close to the central canal with no newly generated neurons migrating away from it up to $5 \mathrm{wpl}$, which would explain the extra time needed by VM cells to recover. Further studies should attempt to demonstrate if the recovery of dopaminergic cell numbers is due to the production of new cells and whether these have their origin in ependymoradial glial progenitors. Our 


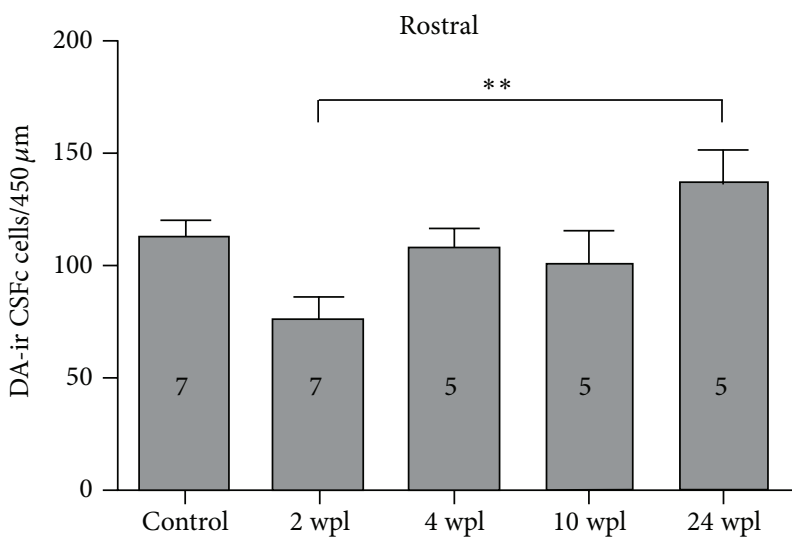

(a)

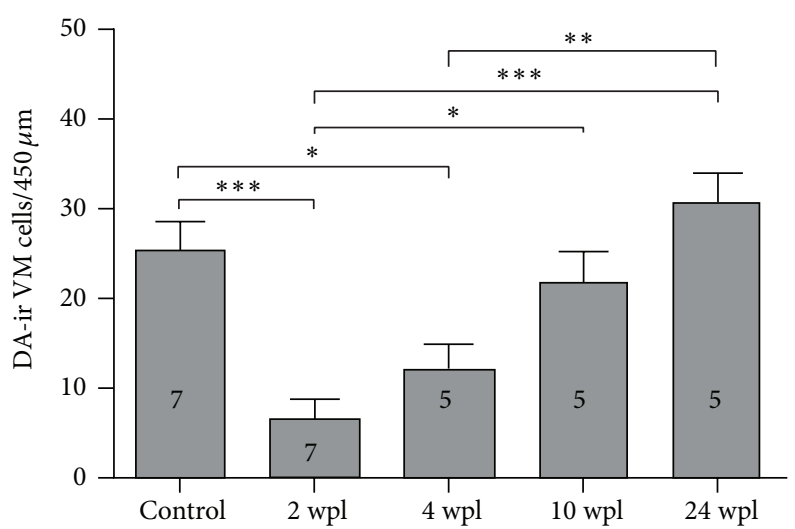

(c)

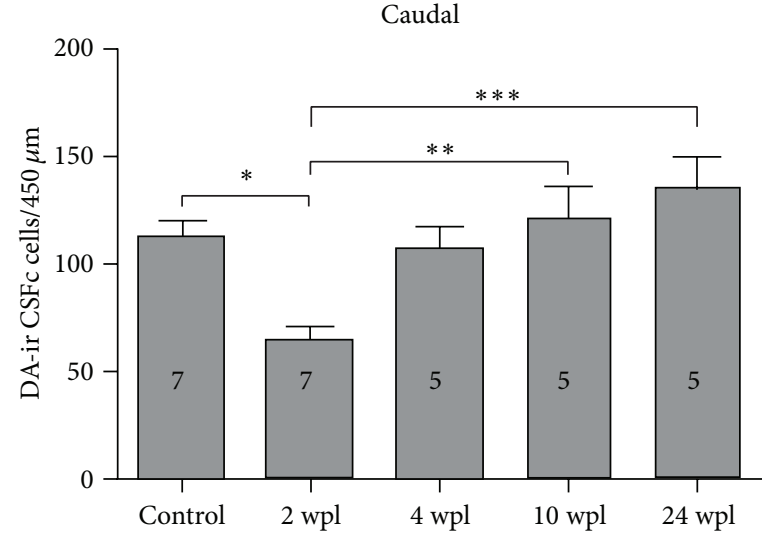

(b)

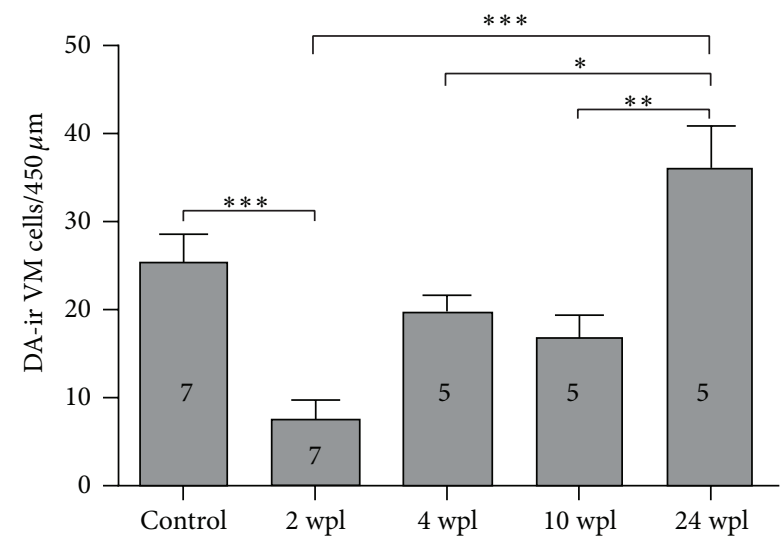

(d)

FIGURE 4: Dopaminergic cell numbers are recovered after a complete spinal cord injury. (a) Quantification of CSFc dopamine-ir cells in the rostral spinal cord (ANOVA, $P=0.0049$ with Bonferroni's posttest, ${ }^{* * *} P<0.0001$ ). (b) Quantification of CSFc dopamine-ir cells in the caudal spinal cord (ANOVA, $P=0.0006$ with Bonferroni's posttest, ${ }^{*} P<0.05,{ }^{* *} P<0.01$, and ${ }^{* * *} P<0.0001$ ). (c) Quantification of VM dopamine-ir cells in the rostral spinal cord (ANOVA, $P<0.0001$ with Bonferroni's posttest, ${ }^{*} P<0.05,{ }^{* *} P<0.01$, and ${ }^{* * *} P<0.0001$ ). (d) Quantification of VM dopamine-ir cells in the caudal spinal cord (ANOVA, $P<0.0001$ with Bonferroni's posttest, ${ }^{*} P<0.05,{ }^{* *} P<0.01$, and $\left.{ }^{* * *} P<0.0001\right)$.

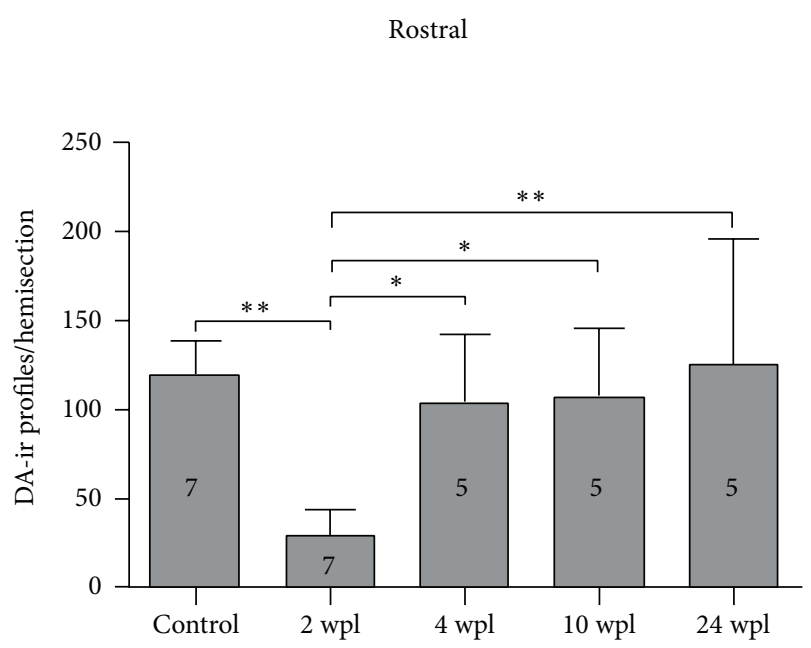

(a)

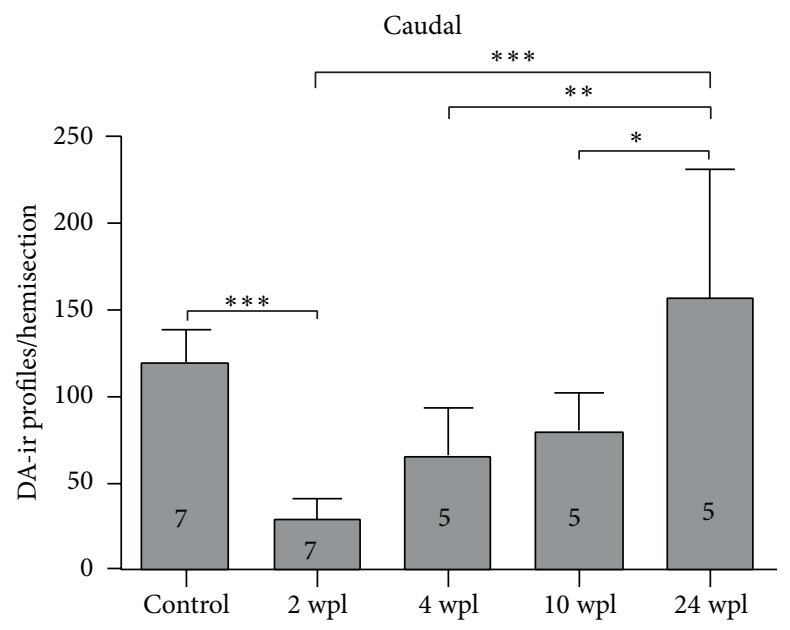

(b)

FIGURE 5: Dopaminergic profile numbers are recovered after a complete spinal cord injury. (a) Quantification of dopaminergic profiles in the rostral spinal cord (ANOVA, $P=0.0009$ with Bonferroni's posttest, ${ }^{*} P<0.05,{ }^{* *} P<0.01$, and ${ }^{* * *} P<0.0001$ ). (b) Quantification of dopaminergic profiles in the caudal spinal cord (ANOVA, $P<0.0001$ with Bonferroni's posttest, ${ }^{*} P<0.05,{ }^{* *} P<0.01$, and ${ }^{* * *} P<0.0001$ ). 


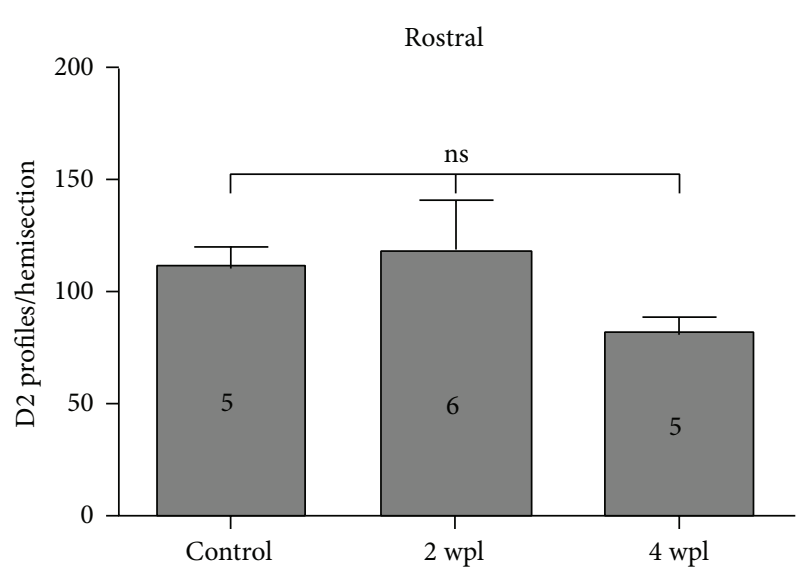

(a)

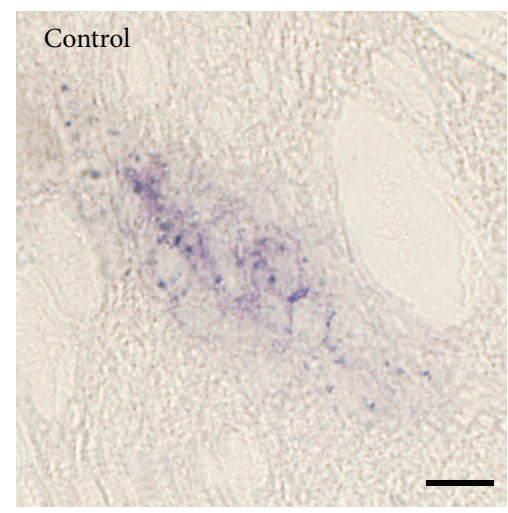

(c)

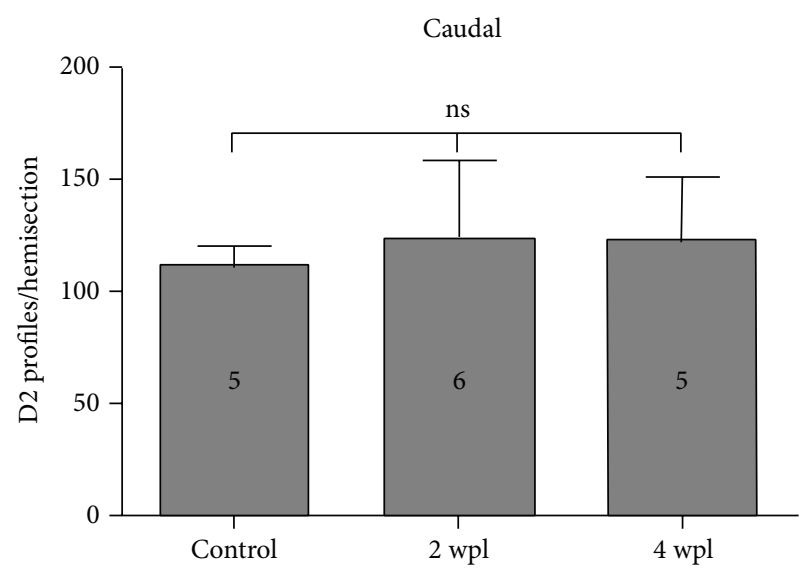

(b)

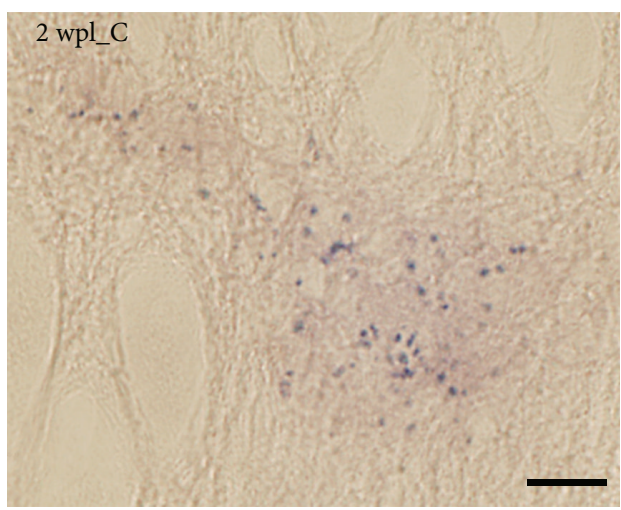

(e)

FIGURE 6: D2 in situ profile numbers do not change after a complete spinal cord injury. (a) Quantification of D2 profiles in the rostral spinal cord. (b) Quantification of D2 profiles in the caudal spinal cord. (c) Photomicrograph showing the D2 receptor expression in the spinal cord of a control larva. (d) Photomicrograph showing the D2 receptor expression in the rostral spinal cord of a 2 wpl larva. (e) Photomicrograph of the $\mathrm{D} 2$ receptor expression in the caudal spinal cord of a $2 \mathrm{wpl}$ larva. In all microphotographs dorsal is at the top. Scale bars $=50 \mu \mathrm{m}$.

study provides a new and interesting model to investigate the spontaneous regeneration of dopaminergic cells after a traumatic injury in vertebrates.

Following the complete spinal cord injury, we observed an initial loss of rostral innervation, not just caudally as one could expect. Obviously, the loss of rostral intrinsic interneurons and their corresponding fibres contributes to this process. However, this might be also related to the dieback of damaged dopaminergic fibres, a process known to occur in axotomized descending axons of lampreys [38]. The initial dieback of rostral dopaminergic fibres has been also reported in adult zebrafish after a complete spinal cord injury [36]. Interestingly, adult zebrafish have no intrinsic dopaminergic cells in the spinal cord [36], which suggests that the reduced rostral innervation after the injury in lampreys could also be explained, at least partially, by a dieback process.

An important difference between the observations in lampreys and zebrafish is that we did not detect a significant increase in the innervation of the rostral spinal cord up to $24 \mathrm{wpl}$ compared to the control situation, instead the number of profiles reached levels similar to control values. In adult zebrafish, dopaminergic fibres sprout after the initial dieback and a significant increased innervation of the rostral spinal cord was observed 13 weeks after the injury [36]. This rostral sprouting leading to increased innervation has been also reported for serotonergic fibres in lampreys [6] and zebrafish $[36,39]$. So, our study reveals interesting and differential feature of the behaviour of dopaminergic fibres after a complete spinal cord injury in lampreys, again stressing the importance of studying this phenomenon in different vertebrate models of spinal cord injury.

Here, we also report for the first time the spontaneous and complete recovery of the dopaminergic innervation of the spinal cord distal to the site of injury in any vertebrate species. The fact that the recovery of the caudal innervation occurred later than that of the rostral spinal cord indicates that part of the distal reinnervation could be due to the regrowth of descending fibres through the site of injury. The full reinnervation of the caudal spinal cord was not observed in another regenerating vertebrate like adult zebrafish [36], even in the presence of behavioural recovery. Our results show that lampreys are more efficient than jawed vertebrates in the recovery of the dopaminergic innervation distal to the site of injury. Future studies should confirm if the caudal 
recovery is due to the regrowth of descending fibres or due to compensation by increased innervation from intrinsic neurons.

The absence of changes in the expression of the D2 receptor after the complete spinal cord injury is also of interest. We have previously reported an acute increase in the expression of the 5-htla after a complete spinal cord injury in lampreys [7]. An increase in the expression of the D4 receptor has been observed following a complete spinal cord injury in adult zebrafish [25]. Our study indicates that different monoaminergic receptors respond in different ways to achieve recovery in regenerating vertebrates and that there is not just a general acute increase in the expression of these receptors due to the initial decrease in monoaminergic innervation. In zebrafish, the $\mathrm{D} 4$ receptor is known to mediate the promoting effect of dopamine on motor neuron regeneration [25]. Interestingly, a recent study using a toxin ablation paradigm has shown that dopamine inhibits the production of new dopaminergic cells in the midbrain of salamanders and that this effect could be mediated by D2 receptors [40]. The lack of changes in the expression of the D2 receptor suggests that it might not play a crucial role during spinal cord regeneration. In any case, our study offers the opportunity to investigate the role of the D2 receptor during the regeneration of dopaminergic cells after a traumatic injury in lampreys.

\section{Conclusions}

Dopaminergic drugs have been proven effective to promote locomotion in mammalian models of spinal cord injury [21-23, 41]. Here, we have shown that larval sea lampreys spontaneously recover their spinal dopaminergic system after a complete spinal cord injury. This model will set the basis for finding molecules implicated in the intrinsic and spontaneous regeneration of dopaminergic cells and fibres in vertebrates. In addition, our anatomical study will help future functional studies on the role of dopamine in the control of locomotion after recovery from a spinal cord injury.

\section{Conflict of Interests}

The authors declare that there is no conflict of interests regarding the publication of this paper.

\section{Authors' Contribution}

Blanca Fernández-López and Daniel Romaus-Sanjurjo contributed equally. Antón Barreiro-Iglesias and María Celina Rodicio contributed equally.

\section{Acknowledgments}

This work was funded by the Spanish Ministry of Science and Innovation, Grant no. BFU2010-17174, to María Celina Rodicio. Sonia Gómez-Fernández and Antón Barreiro-Iglesias were supported by predoctoral and postdoctoral grants, respectively, from the Xunta de Galicia (Galicia, Spain).

\section{References}

[1] M. C. Rodicio and A. Barreiro-Iglesias, "Lampreys as an animal model in regeneration studies after spinal cord injury," Revista de Neurología, vol. 55, no. 3, pp. 157-166, 2012.

[2] A. J. Jacobs, G. P. Swain, J. A. Snedeker, D. S. Pijak, L. J. Gladstone, and M. E. Selzer, "Recovery of neurofilament expression selectively in regenerating reticulospinal neurons," The Journal of Neuroscience, vol. 17, no. 13, pp. 5206-5220, 1997.

[3] J. Armstrong, L. Zhang, and A. D. McClellan, "Axonal regeneration of descending and ascending spinal projection neurons in spinal cord-transected larval lamprey," Experimental Neurology, vol. 180, no. 2, pp. 156-166, 2003.

[4] M. E. Cornide-Petronio, M. S. Ruiz, A. Barreiro-Iglesias, and M. C. Rodicio, "Spontaneous regeneration of the serotonergic descending innervation in the sea lamprey after spinal cord injury," Journal of Neurotrauma, vol. 28, no. 12, pp. 2535-2540, 2011.

[5] G. Zhang, I. V. Pizarro, G. P. Swain, S. H. Kang, and M. E. Selzer, "Neurogenesis in the lamprey central nervous system following spinal cord transection," Journal of Comparative Neurology, vol. 522, no. 6, pp. 1316-1332, 2014.

[6] A. H. Cohen, M. Abdelnabi, G. Li, M. A. Ottinger, and L. Chakrabarti, "Changes in distribution of serotonin induced by spinal injury in larval lampreys: evidence from immunohistochemistry and HPLC," Journal of Neurotrauma, vol. 22, no. 1, pp. 172-188, 2005.

[7] M. E. Cornide-Petronio, B. Fernández-López, A. BarreiroIglesias, and M. C. Rodicio, "Traumatic injury induces changes in the expression of the serotonin $1 \mathrm{~A}$ receptor in the spinal cord of lampreys," Neuropharmacology, vol. 77, pp. 369-378, 2014.

[8] E. Svensson, O. Kim, and D. Parker, "Altered GABA and somatostatin modulation of proprioceptive feedback after spinal cord injury in lamprey," Neuroscience, vol. 235, pp. 109-118, 2013.

[9] B. Fernández-López, S. M. Valle-Maroto, A. Barreiro-Iglesias, and M. C. Rodicio, "Neuronal release and successful astrocyte uptake of aminoacidergic neurotransmitters after spinal cord injury in lampreys," Glia, vol. 62, no. 8, pp. 1254-1269, 2014.

[10] B. Fernández-López, Glutamatergic spinal system in the sea lamprey. Changes after spinal cord injury and during regeneration [Doctoral thesis], University of Santiago de Compostela, 2014.

[11] S. A. Sharples, K. Koblinger, J. M. Humphreys, and P. J. Whelan, "Dopamine: a parallel pathway for the modulation of spinal locomotor networks," Frontiers in Neural Circuits, vol. 8, article 55, 2014.

[12] D. R. McPherson and C. P. Kemnitz, "Modulation of lamprey fictive swimming and motoneuron physiology by dopamine, and its immunocytochemical localization in the spinal cord," Neuroscience Letters, vol. 166, no. 1, pp. 23-26, 1994.

[13] J. Schotland, O. Shupliakov, M. Wikström et al., "Control of lamprey locomotor neurons by colocalized monoamine transmitters," Nature, vol. 374, no. 6519, pp. 266-268, 1995.

[14] E. Svensson, M. A. Wikström, R. H. Hill, and S. Grillner, "Endogenous and exogenous dopamine presynaptically inhibits glutamatergic reticulospinal transmission via an action of $\mathrm{D}_{2}$ receptors on $\mathrm{N}$-type $\mathrm{Ca}^{2+}$ channels," European Journal of $\mathrm{Neu}$ roscience, vol. 17, no. 3, pp. 447-454, 2003.

[15] C. P. Kemnitz, T. R. Strauss, D. M. Hosford, and J. T. Buchanan, "Modulation of swimming in the lamprey, Petromyzon marinus, by serotonergic and dopaminergic drugs," Neuroscience Letters, vol. 201, no. 2, pp. 115-118, 1995. 
[16] S. Clemens, A. Belin-Rauscent, J. Simmers, and D. Combes, "Opposing modulatory effects of D1- and D2-like receptor activation on a spinal central pattern generator," Journal of Neurophysiology, vol. 107, no. 8, pp. 2250-2259, 2012.

[17] H. Barbeau and S. Rossignol, "Initiation and modulation of the locomotor pattern in the adult chronic spinal cat by noradrenergic, serotonergic and dopaminergic drugs," Brain Research, vol. 546, no. 2, pp. 250-260, 1991.

[18] O. Kiehn and O. Kjærulff, "Spatiotemporal characteristics of 5HT and dopamine-induced rhythmic hindlimb activity in the in vitro neonatal rat," Journal of Neurophysiology, vol. 75, no. 4, pp. 1472-1482, 1996.

[19] G. Barrière, N. Mellen, and J. R. Cazalets, "Neuromodulation of the locomotor network by dopamine in the isolated spinal cord of newborn rat," European Journal of Neuroscience, vol. 19, no. 5, pp. 1325-1335, 2004.

[20] S. A. Sharples, J. M. Humphreys, K. Mayr, A. Krajacic, S. A. Dhoopar, and N. Delaloye, Dopaminergic Contribution to Locomotion in the Neonatal and Adult Mouse, Poster 559.11/ZZ15, Society for Neuroscience, San Diego, Calif, USA, 2013.

[21] N. P. Lapointe and P. A. Guertin, "Synergistic effects of D1/51 and 5-HT11A/71 receptor agonists on locomotor movement induction in complete spinal cord-transected mice," Journal of Neurophysiology, vol. 100, no. 1, pp. 160-168, 2008.

[22] P. A. Guertin, R.-V. Ung, and P. Rouleau, "Oral administration of a tri-therapy for central pattern generator activation in paraplegic mice: proof-of-concept of efficacy," Biotechnology Journal, vol. 5, no. 4, pp. 421-426, 2010.

[23] R. van den Brand, J. Heutschi, Q. Barraud et al., "Restoring voluntary control of locomotion after paralyzing spinal cord injury," Science, vol. 336, no. 6085, pp. 1182-1185, 2012.

[24] A. M. Lambert, J. L. Bonkowsky, and M. A. Masino, "The conserved dopaminergic diencephalospinal tract mediates vertebrate locomotor development in zebrafish larvae," Journal of Neuroscience, vol. 32, no. 39, pp. 13488-13500, 2012.

[25] M. M. Reimer, A. Norris, J. Ohnmacht et al., "Dopamine from the brain promotes spinal motor neuron generation during development and adult regeneration," Developmental Cell, vol. 25, no. 5, pp. 478-491, 2013.

[26] K. Koblinger, T. Füzesi, J. Ejdrygiewicz, A. Krajacic, J. S. Bains, and P. J. Whelan, "Characterization of All neurons projecting to the spinal cord of mice," PLoS ONE, vol. 9, no. 10, Article ID e109636, 2014.

[27] A. Barreiro-Iglesias, V. Villar-Cerviño, R. Anadón, and M. C. Rodicio, "Descending brain-spinal cord projections in a primitive vertebrate, the lamprey: cerebrospinal fluid-contacting and dopaminergic neurons," Journal of Comparative Neurology, vol. 511, no. 6, pp. 711-723, 2008.

[28] A. Barreiro-Iglesias, V. Villar-Cerviño, R. Anadón, and M. C. Rodicio, "Dopamine and gamma-aminobutyric acid are colocalized in restricted groups of neurons in the sea lamprey brain: insights into the early evolution of neurotransmitter colocalization in vertebrates," Journal of Anatomy, vol. 215, no. 6, pp. 601-610, 2009.

[29] B. Fernández-López, A. Barreiro-Iglesias, and M. C. Rodicio, "Confocal microscopy used for the semiautomatic quantification of the changes in aminoacidergic fibers during spinal cord regeneration," Neuromethods, vol. 87, pp. 239-250, 2014.

[30] V. Kuscha, A. Barreiro-Iglesias, C. G. Becker, and T. Becker, "Plasticity of tyrosine hydroxylase and serotonergic systems in the regenerating spinal cord of adult zebrafish," Journal of Comparative Neurology, vol. 520, no. 5, pp. 933-951, 2012.
[31] M. E. Cornide-Petronio, R. Anadón, A. Barreiro-Iglesias, and M. C. Rodicio, "Serotonin 1A receptor (5-HT1A) of the sea lamprey: CDNA cloning and expression in the central nervous system," Brain Structure and Function, vol. 218, no. 5, pp. 13171335, 2013.

[32] B. Robertson, I. Huerta-Ocampo, J. Ericsson et al., "The dopamine D2 receptor gene in lamprey, its expression in the striatum and cellular effects of D2 receptor activation," PLoS ONE, vol. 7, no. 4, Article ID e35642, 2012.

[33] J. Pérez-Fernández, M. Stephenson-Jones, S. M. Suryanarayana, B. Robertson, and S. Grillner, "Evolutionarily conserved organization of the dopaminergic system in lamprey: SNc/VTA afferent and efferent connectivity and D2 receptor expression," Journal of Comparative Neurology, vol. 522, no. 17, pp. 37753794, 2014.

[34] J. L. Schotland, O. Shupliakov, S. Grillner, and L. Brodin, "Synaptic and nonsynaptic monoaminergic neuron systems in the lamprey spinal cord," The Journal of Comparative Neurology, vol. 372, no. 2, pp. 229-244, 1996.

[35] M. M. Reimer, I. Sörensen, V. Kuscha et al., "Motor neuron regeneration in adult zebrafish," The Journal of Neuroscience, vol. 28, no. 34, pp. 8510-8516, 2008.

[36] V. Kuscha, S. L. Frazer, T. B. Dias, M. Hibi, T. Becker, and C. G. Becker, "Lesion-induced generation of interneuron cell types in specific dorsoventral domains in the spinal cord of adult zebrafish," Journal of Comparative Neurology, vol. 520, no. 16, pp. 3604-3616, 2012.

[37] A. Barreiro-Iglesias, "Targeting ependymal stem cells in vivo as a non-invasive therapy for spinal cord injury," Disease Models and Mechanisms, vol. 3, no. 11-12, pp. 667-668, 2010.

[38] L.-Q. Jin, G. Zhang, C. Jamison Jr., H. Takano, P. G. Haydon, and M. E. Selzer, "Axon regeneration in the absence of growth cones: acceleration by cyclic AMP," Journal of Comparative Neurology, vol. 515, no. 3, pp. 295-312, 2009.

[39] A. Barreiro-Iglesias, “Evorego': studying regeneration to understand evolution, the case of the serotonergic system," Brain, Behavior and Evolution, vol. 79, no. 1, pp. 1-3, 2012.

[40] D. A. Berg, M. Kirkham, H. Wang, J. Frisén, and A. Simon, "Dopamine controls neurogenesis in the adult salamander midbrain in homeostasis and during regeneration of dopamine neurons," Cell Stem Cell, vol. 8, no. 4, pp. 426-433, 2011.

[41] N. P. Lapointe, P. Rouleau, R.-V. Ung, and P. A. Guertin, "Specific role of dopamine D1 receptors in spinal network activation and rhythmic movement induction in vertebrates," Journal of Physiology, vol. 587, no. 7, pp. 1499-1511, 2009. 

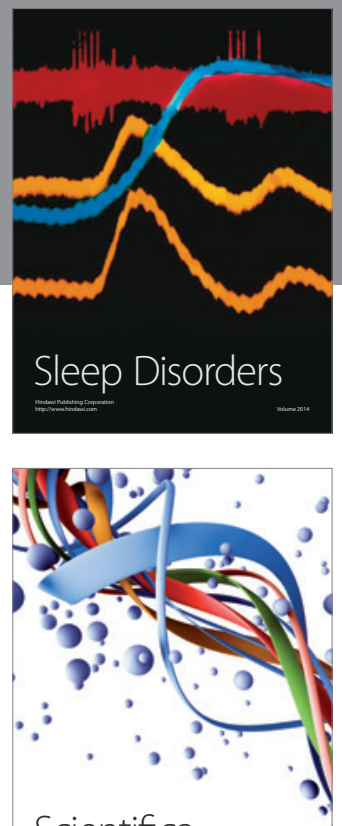

Scientifica
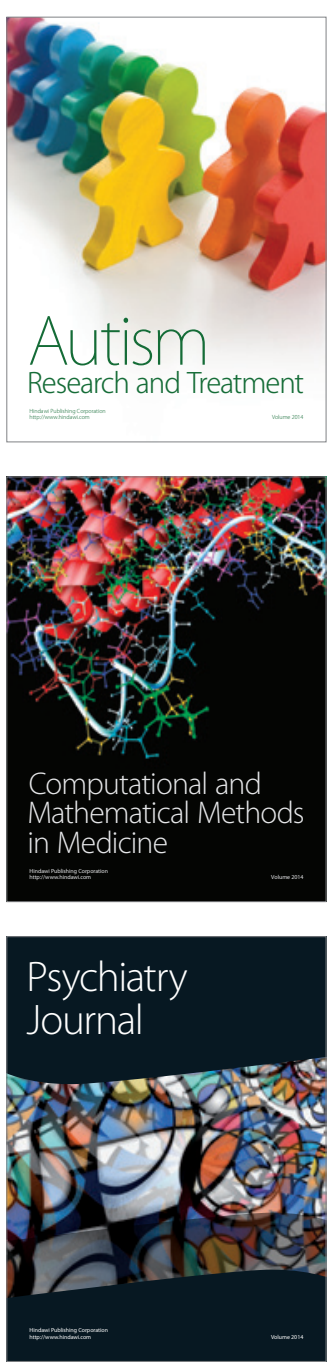
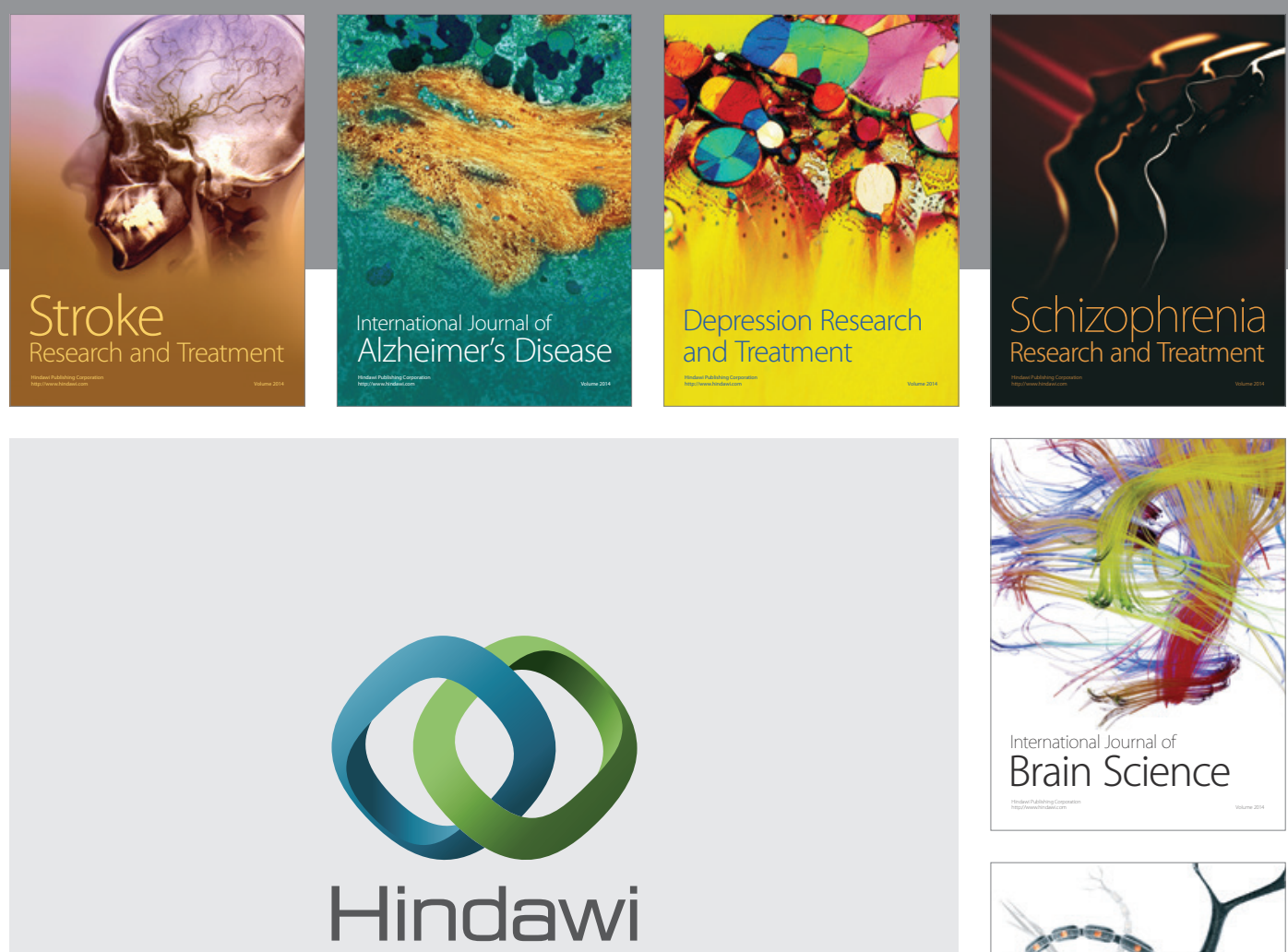

Submit your manuscripts at

http://www.hindawi.com
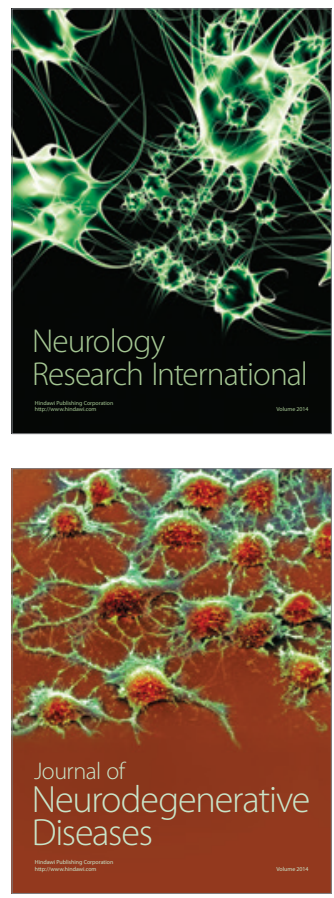

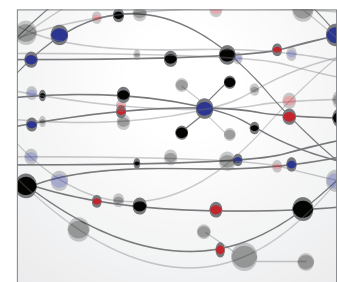

The Scientific World Journal
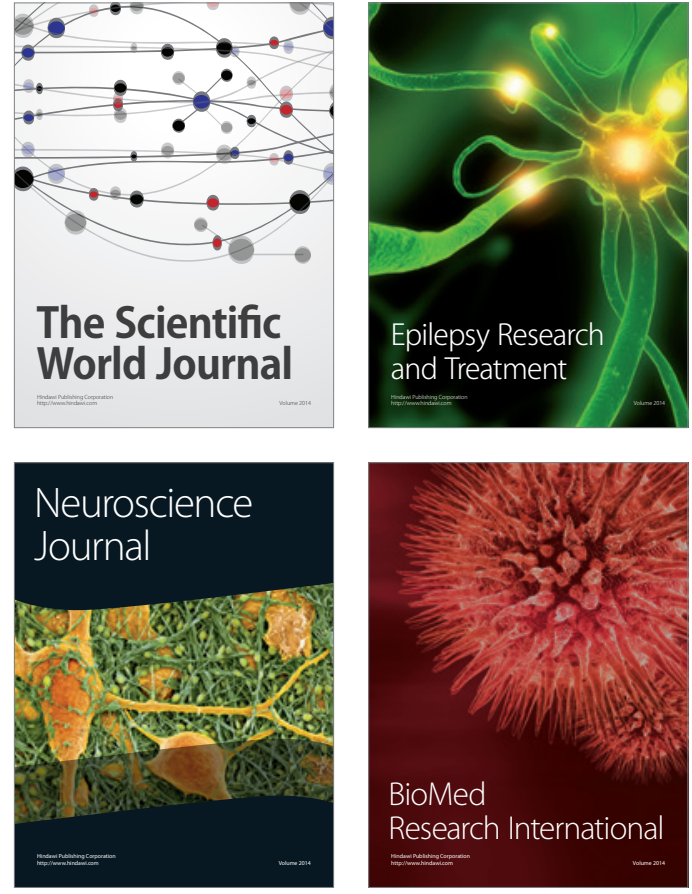

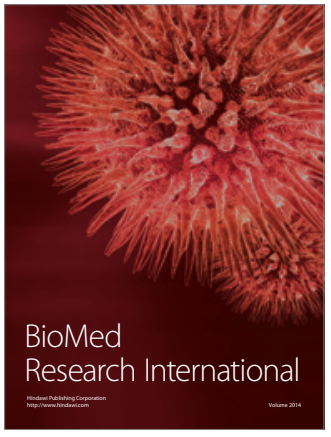

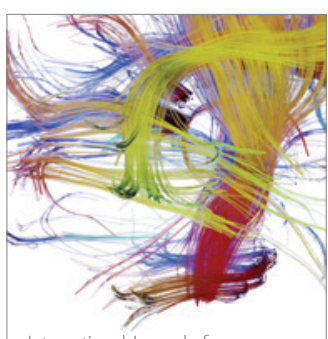

Brain Science

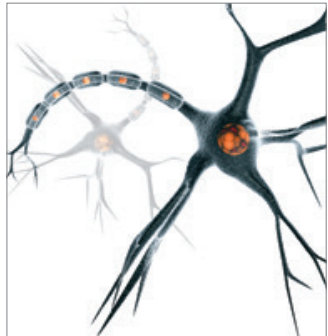

Neural Plasticity
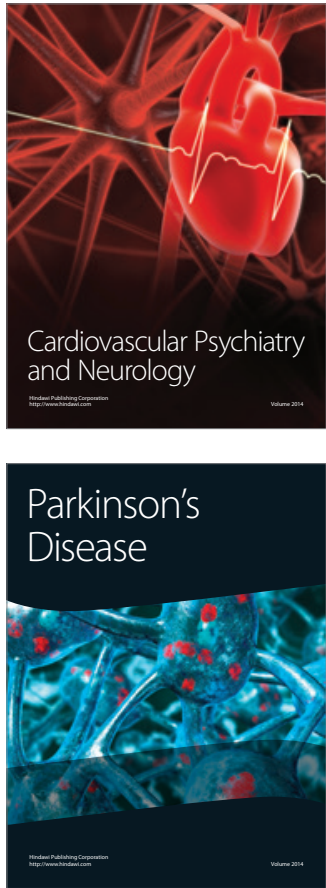